\title{
Characteristics of Patients Who Achieve Serum Phosphorus Control on Sucroferric Oxyhydroxide or Sevelamer Carbonate: A post hoc Analysis of a Phase 3 Study
}

\author{
Adrian C. Covic ${ }^{a}$ Stuart M. Sprague ${ }^{b}$ Anjay Rastogi ${ }^{c}$ Markus Ketteler ${ }^{d}$ \\ Sebastian Walpen ${ }^{e}$ Amandine Perrin $^{f}$ Jürgen Floege ${ }^{g}$
}

${ }^{a}$ Nephrology Clinic and Dialysis and Transplantation Center, Grigore T. Popa University of Medicine and Pharmacy, Iași, Romania; borthShore University Health System, University of Chicago, Pritzker School of Medicine, Evanston, IL, USA; 'Division of Nephrology, University of California, Los Angeles, CA, USA; dDepartment of General Internal

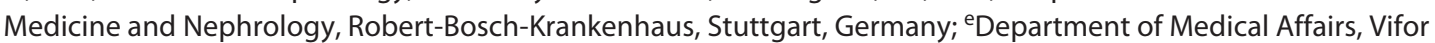
Pharma, Glattbrugg, Switzerland; 'Department of Biometrics, Vifor Pharma, Glattbrugg, Switzerland; 9Division of Nephrology, RWTH University Hospital Aachen, Aachen, Germany

\section{Keywords}

Sucroferric oxyhydroxide - Dialysis - Sevelamer carbonate · Chronic kidney disease $\cdot$ Phosphate binder

\footnotetext{
Abstract

Introduction: Control of hyperphosphatemia in patients on dialysis remains a major challenge. Objective: This study evaluated predictors of serum phosphorus (sP) control among dialysis patients treated with noncalcium, oral phosphate binder therapy in a phase 3 clinical trial. Methods: Post hoc analyses were performed using data for patients with hyperphosphatemia who received 52 weeks of treatment with sucroferric oxyhydroxide (SFOH) or sevelamer carbonate (sevelamer). Patients were categorized into those who achieved sP control ( $n=302$; defined as $\mathrm{sP} \leq 5.5 \mathrm{mg} / \mathrm{dL}$ at week 52), and those with uncontrolled sP ( $n=195$; sP $>5.5$ $\mathrm{mg} / \mathrm{dL}$ at week 52). Because SFOH and sevelamer have previously demonstrated similar effects on chronic kidney dis-
}

ease-mineral-bone disorder parameters in this study, the treatment groups were pooled. Results: Average age at baseline was higher among sP-controlled versus sP-uncontrolled patients (56.9 vs. 53.4 years; $p=0.005$ ). Baseline sP levels were significantly lower among $\mathrm{sP}$-controlled versus sP-uncontrolled patients (7.30 vs. $7.85 \mathrm{mg} / \mathrm{dL} ; p<0.001)$, and $\mathrm{SP}$ reductions from baseline were significantly greater in the sP-controlled group ( -2.89 vs. $-0.99 \mathrm{mg} / \mathrm{dL}$ at week $52 ; p<$ $0.001)$. Logistic regression analysis identified higher baseline sP levels (odds ratio [OR] $=0.86,95 \%$ confidence interval $[\mathrm{Cl}]$ : $0.765-0.960)$, no concomitant active vitamin $D$ therapy use (OR $=0.51,95 \% \mathrm{Cl}: 0.328-0.804)$, and higher body mass index at baseline $(\mathrm{OR}=0.96,95 \% \mathrm{Cl}$ : 0.937-0.992) as significant predictors of uncontrolled sP. Conclusion: This analysis indicates that $\mathrm{SP}$ control may be more challenging in younger patients with high sP levels. Closer monitoring and management of serum phosphorus levels may be required in this population.

(C) 2020 The Author(s)

Published by S. Karger AG, Basel

\begin{tabular}{ll}
\hline karger@karger.com & $\begin{array}{l}\text { ( ) } 2020 \text { The Author(s) } \\
\text { Published by S. Karger AG, Basel }\end{array}$ \\
www.karger.com/nef & This article is licensed under the Creative Commons Attribution- \\
Karger & NonCommercial-NoDerivatives 4.0 International License (CC BY- \\
NC-ND) (http://www.karger.com/Services/OpenAccessLicense). \\
Usage and distribution for commercial purposes as well as any dis- \\
tribution of modified material requires written permission.
\end{tabular}




\section{Introduction}

Hyperphosphatemia is common in patients with advanced-stage chronic kidney disease (CKD) and is a key component of CKD-mineral and bone disorder (CKDMBD), a condition associated with abnormalities in other biochemical parameters, including elevated levels of serum parathyroid hormone $(\mathrm{PTH})$ and fibroblast growth factor-23 (FGF-23) [1]. Serious complications of CKDMBD include abnormalities in bone turnover, vascular calcification, and cardiovascular disease $[1,2]$. High levels of serum phosphorus (sP), PTH, and FGF-23 have been independently associated with a greater risk of mortality in patients with advanced-stage CKD undergoing dialysis [3-5].

The majority of dialysis patients are prescribed oral phosphate binders for the management of their hyperphosphatemia (defined as $\mathrm{sP}>5.5 \mathrm{mg} / \mathrm{dL}$ ) and CKDMBD; however, approximately $40 \%$ of hemodialysis patients receiving phosphate binders have serum phosphorus levels above the Kidney Disease Outcomes Quality Initiative (KDOQI) target range $(3.5-5.5 \mathrm{mg} / \mathrm{dL}$ ) [6-9]. Selection of an effective and well-tolerated phosphate binder therapy is therefore paramount. Clinical study evidence suggests that the use of calcium-based phosphate binders is associated with increased mortality, compared with the use of noncalcium-containing binders $[10,11]$. Noncalcium-containing phosphate binders currently approved for the treatment of hyperphosphatemia in dialysis patients include sevelamer carbonate (sevelamer), lanthanum, and the iron-based phosphate binders, ferric citrate and sucroferric oxyhydroxide [12-14]. A phase 3 study and subsequent extension study in dialysis patients with hyperphosphatemia demonstrated that sucroferric oxyhydroxide was well tolerated and displayed similar efficacy with regard to sustained serum phosphorus control over 1 year, compared with sevelamer carbonate, but with a lower daily pill burden $[15,16]$.

In addition to the choice of phosphate binder, the potential to identify patients who are likely to respond to phosphate binder therapy may help optimize therapy for hyperphosphatemia in dialysis patients. To assess this, a post hoc analysis of the phase 3 study and its extension was performed to evaluate predictors of serum phosphorus control in dialysis patients receiving sucroferric oxyhydroxide or sevelamer. Because both phosphate binders had a comparable serum phosphorus-lowering efficacy and displayed similar effects on CKD-MBD parameters during the 52-week treatment period [17], the two treatment groups were pooled for this post hoc analysis.

sP Control with Sucroferric Oxyhydroxide or Sevelamer Carbonate

\section{Materials and Methods}

\section{Study Design}

The initial phase 3 trial (NCT01324128) was a multicenter, open-label, active-controlled study. The trial design has been described elsewhere $[15,16]$. In brief, following 2-4 weeks' washout from their previous phosphate binder(s), 1,059 eligible patients with serum phosphorus concentrations of $\geq 6.0 \mathrm{mg} / \mathrm{dL}(\geq 1.94$ $\mathrm{mmol} / \mathrm{L})$ were randomized $(2: 1)$ to receive sucroferric oxyhydroxide $(1.0-3.0 \mathrm{~g} /$ day $[2-6$ tablets/day]; $n=710)$ or sevelamer $(2.4-$ $14.4 \mathrm{~g} /$ day [3-18 tablets/day]; starting dose of $4.8 \mathrm{~g} /$ day [6 tablets/ day]; $n=349$ ) for 12 weeks' dose titration (weeks 1-12). This was comprised of 8 weeks during which dose titration was permitted for efficacy or tolerability, followed by 4 weeks during which dose changes were permitted only for tolerability. The dose-titration period was followed by 12 weeks' maintenance (weeks 13-24). Doses of study treatments were titrated to achieve predefined serum phosphorus concentrations of between $2.5 \mathrm{mg} / \mathrm{dL}(0.81$ $\mathrm{mmol} / \mathrm{L})$ and $5.5 \mathrm{mg} / \mathrm{dL}(1.78 \mathrm{mmol} / \mathrm{L})$. Patients who met the eligibility criteria were allowed to enter the extension study (NCT01464190), continuing the same treatment and dosage they were receiving at the end of the initial study for a further 28 weeks.

\section{Participants}

The eligibility criteria for the initial phase 3 study have been described previously [15]. In brief, eligible patients ( $\geq 18$ years of age) had a history of hyperphosphatemia and were receiving stable doses of one or more phosphate binders for $\geq 1$ month prior to screening. Eligible patients were undergoing maintenance hemodialysis 3 times per week or peritoneal dialysis $\geq 3$ months before screening and had serum phosphate levels $\geq 6.0 \mathrm{mg} / \mathrm{dL}(\geq 1.94$ $\mathrm{mmol} / \mathrm{L}$ ) during washout. Patients were ineligible if, at screening, they had intact PTH (iPTH) levels of $>800 \mathrm{ng} / \mathrm{L}(88 \mathrm{pmol} / \mathrm{L})$ or serum ferritin $>2,000 \mu \mathrm{g} / \mathrm{L}$. Patients receiving noncalcium-based phosphate binders with hypercalcemia (total serum calcium $>10.50 \mathrm{mg} / \mathrm{dL}$ ) or patients with hypocalcemia (total serum calcium $<7.6 \mathrm{mg} / \mathrm{dL}$ ) at screening were also excluded.

\section{Assessments and Analysis Sets}

Details of efficacy and safety assessments during the initial study and extension have also been described previously $[15,16]$. In brief, serum concentrations of biochemical parameters were assessed at baseline (week 0 ), predefined time points over 1 year, and end of study (week 52). Parameters evaluated included serum phosphorus, iPTH, and FGF-23. Analysis of serum samples was performed at one of the two central laboratories using standard validated methods. FGF-23 levels were assessed using Human Intact FGF-23 ELISA Kit (Immutopics, Inc.). iPTH levels were assessed using the Advia Centaur XP iPTH assay (Siemens Healthcare Diagnostic, Inc.). In the original phase 3 study, efficacy endpoints were assessed using the "full analysis set," defined as patients randomized to treatment who received at least one dose of study medication and had at least one post-baseline evaluable efficacy assessment. Serum albumin and serum total protein were evaluated using standard laboratory techniques.

The main post hoc analyses presented in this article were performed on the "main analysis set" (MAS), which consisted of patients in the full analysis set who had a serum phosphorus measurement available at week 52 . In the MAS, patients were defined as having controlled serum phosphorus ("sP-controlled") if they 
achieved serum phosphorus levels of $\leq 5.5 \mathrm{mg} / \mathrm{dL}(\leq 1.78 \mathrm{mmol} / \mathrm{L})$ at week 52 on either phosphate binder treatment, whereas those patients who had serum phosphorus $>5.5 \mathrm{mg} / \mathrm{dL}(>1.78 \mathrm{mmol} / \mathrm{L})$ at week 52 were defined as "sP-uncontrolled."

A supporting post hoc analysis was performed on the "supporting analysis set" (SAS), which consisted of patients in the full analysis set who had at least 3 serum phosphorus readings between week 12 and week 52 . This analysis aimed to include patients who may have achieved serum phosphorus control for the majority of the treatment period but were excluded from the main analysis potentially due to a transient increase in their serum phosphorus levels at week 52. In the SAS, patients were defined as having serum phosphorus control ("sP-controlled") if two-thirds of their serum phosphorus measurements between week 12 and week 52 were $\leq 5.5 \mathrm{mg} / \mathrm{dL}(\leq 1.78 \mathrm{mmol} / \mathrm{L})$. Conversely, patients were defined as "sP-uncontrolled" if two-thirds of serum phosphorus readings taken in the same time period were $>6.0 \mathrm{mg} / \mathrm{dL}(>1.94 \mathrm{mmol} / \mathrm{L})$. Patients who did not meet either set of these criteria were not included in the SAS. To evaluate potential differences in tolerability to sucroferric oxyhydroxide or sevelamer treatment among sPcontrolled versus sP-uncontrolled patients, treatment-emergent adverse event (TEAE) profiles were compared using the MAS population.

\section{Statistical Analysis}

The sucroferric oxyhydroxide group and sevelamer group were pooled for the purposes of the main and supporting analyses. However, separate analyses were also performed to examine any treatment differences between the two treatment groups. For both the main and supporting analyses, mean $( \pm S D)$ serum concentrations of phosphorus and iPTH and median (25th and 75th percentiles) serum concentration of FGF-23 were displayed graphically at baseline, week 24 , and week 52 for sP-controlled and sP-uncontrolled patients.

Statistical tests were performed using 2-sided tests at a significance level of 0.05 and were conducted using Statistical Analysis System ${ }^{\circledR}$ version 9.2 or later (SAS Institute, Cary, NC, USA). The Kruskal-Wallis test was used for continuous demographic variables, and the Cochran-Mantel-Haenszel test used for categorical demographic variables. Baseline-adjusted analysis of variance (ANOVA) was used for laboratory results (except for FGF-23, for which a baseline-adjusted generalized linear model on rank data was used). No adjustment for multiple testing was performed during the statistical analysis, and $p$ values should be interpreted descriptively. Some significant findings were expected to have occurred by chance. Therefore, undue consideration would not be given to any particular significant difference.

A logistic regression was performed on the MAS to identify demographic and clinical predictors of serum phosphorus control at week $52(\leq 5.5 \mathrm{or}>5.5 \mathrm{mg} / \mathrm{dL})$, which was analyzed as the dependent (outcome) variable. The model was constructed using demographic and clinical variables of interest that achieved a threshold significance level of $p<0.2$ in a univariate screening (see online suppl. Table 1; see www.karger.com/doi/10.1159/000507258 for all online suppl. material). A stepwise backward selection was then applied to determine which specific variables had a statistically significant effect on outcome in the best-fitted model, based on a threshold significance level of $p<0.05$.

Adherence to phosphate binder therapy was calculated for the MAS only, based on the recorded number of tablets actually taken, relative to the number of tablets expected to be taken (according to the dose over the patient's participation in the study), using dispensing and return records:

Treatment adherence $=\left(\frac{\text { Total number of tablets taken }}{\text { Number of tablets expected to be taken }}\right) \times 100$.

Patients were recorded as being adherent if their adherence was within $70-120 \%$ of the expected tablet intake.

\section{Results}

\section{Patient Disposition and Demographics}

The patient disposition of the initial phase 3 trial and extension study has been described previously [16]. Of the 1,041 patients included in the full analysis set of the initial phase 3 study, 497 (48\%) had a serum phosphorus measurement available at week 52 and were eligible for inclusion in the MAS (Table 1). In total, there were 302 (61\%) patients in the sP-controlled group and 195 (39\%) patients in the sP-uncontrolled group. Baseline characteristics of patients in these groups were broadly similar, although the mean age of patients in the sP-controlled group was significantly higher than in the sP-uncontrolled group ( 56.9 vs. 53.4 years; $p=0.005$ ). Dialysis adequacy (assessed by Kt/V) among patients on hemodialysis was also significantly higher in the sP-controlled group versus the sP-uncontrolled group $(p=0.003)$.

The SAS included 569 patients (55\% of the full analysis set from the initial phase 3 study), of which the majority (74.9\%) were defined as having achieved serum phosphorus control during the study (online suppl. Table 2). In the SAS, the mean age of patients with controlled serum phosphorus was also significantly higher than those with uncontrolled serum phosphorus (58.3 vs. 50.6 years; $p<$ 0.001 ). Baseline body mass index (BMI) and body weight were also significantly lower among sP-controlled versus sP-uncontrolled patients (online suppl. Table 2).

\section{Efficacy}

\section{Serum Phosphorus}

In the MAS, mean baseline serum phosphorus levels were significantly lower among those patients with controlled versus uncontrolled serum phosphorus levels at week 52 ( 7.30 vs. 7.85 mg/dL; $p<0.001$; Fig. 1a). Reductions in serum phosphorus from baseline to week 24 $(-2.44$ vs. $-2.13 \mathrm{mg} / \mathrm{dL})$ and week 52 ( -2.89 vs. $-0.99 \mathrm{mg} /$ $\mathrm{dL})$ were significantly greater among $\mathrm{sP}$-controlled versus $\mathrm{sP}$-uncontrolled patients, respectively $(p<0.001$ for both time points). In the sP-controlled group, the initial reductions in mean serum phosphorus from baseline to 
Table 1. Baseline patient demographics and clinical characteristics (main analysis set, $N=497$ )

\begin{tabular}{|c|c|c|}
\hline Parameter & $\begin{array}{l}\text { sP-controlled } \\
\text { patients }(n=302)\end{array}$ & $\begin{array}{l}\text { sP-uncontrolled } \\
\text { patients }(n=195)\end{array}$ \\
\hline Mean (SD) age, years ${ }^{\mathrm{a}}$ & $56.9(13.9)^{*}$ & $53.4(13.5)$ \\
\hline Male, $n(\%)^{\mathrm{b}}$ & $180(59.6)$ & $115(59.0)$ \\
\hline \multicolumn{3}{|l|}{ Race, $n(\%)^{\mathrm{b}}$} \\
\hline White & $239(79.1)$ & $155(79.5)$ \\
\hline Black/African American & $51(16.9)$ & $35(17.9)$ \\
\hline Asian & $5(1.7)$ & $2(1.0)$ \\
\hline Native Hawaiian or other Pacific Islander & $3(1.0)$ & $2(1.0)$ \\
\hline Other & $4(1.3)$ & $1(0.5)$ \\
\hline \multicolumn{3}{|l|}{ Ethnicity, $n(\%)^{\mathrm{b}}$} \\
\hline Non-Hispanic & $264(87.4)$ & $172(88.2)$ \\
\hline Hispanic or Latino & $38(12.6)$ & $23(11.8)$ \\
\hline \multicolumn{3}{|l|}{ Region, $n(\%)^{\mathrm{b}}$} \\
\hline USA & $144(47.7)$ & $79(40.5)$ \\
\hline EU & $56(18.5)$ & $36(18.5)$ \\
\hline ROW & $102(33.8)$ & $80(41.0)$ \\
\hline Mean (SD) weight, $\mathrm{kg}^{\mathrm{a}}$ & $81.7(20.5)$ & $84.6(20.6)$ \\
\hline Mean body mass index, $\mathrm{kg} / \mathrm{m}^{2 \mathrm{a}}$ & $28.6(6.6)$ & $29.7(7.0)$ \\
\hline \multicolumn{3}{|l|}{ Reasons for ESRD, $n(\%)^{\mathrm{b}}$} \\
\hline Hypertension & $79(26.2)$ & $41(21.0)$ \\
\hline Glomerulonephritis & $72(23.8)$ & $51(26.2)$ \\
\hline Diabetic nephropathy & $69(22.8)$ & $54(27.7)$ \\
\hline Pyelonephritis & $11(3.6)$ & $7(3.6)$ \\
\hline Polycystic kidney disease & $24(7.9)$ & $19(9.7)$ \\
\hline Interstitial nephritis & $8(2.6)$ & $6(3.1)$ \\
\hline Hydronephrosis & $4(1.3)$ & $3(1.5)$ \\
\hline Congenital & $7(2.3)$ & $3(1.5)$ \\
\hline Other & $28(9.3)$ & $11(5.6)$ \\
\hline Months since ESRD diagnosis, median (range) ${ }^{\mathrm{a}, \mathrm{c}}$ & $44.8(0.4-396.8)$ & $43.3(3.5-381.6)$ \\
\hline Months since first dialysis, median (range) ${ }^{\mathrm{a}, \mathrm{d}}$ & $35.0(2.5-396.8)$ & $32.9(3.5-276.4)$ \\
\hline $\mathrm{HD}, n(\%)^{\mathrm{b}}$ & $273(90.4)$ & $180(92.3)$ \\
\hline $\mathrm{PD}, n(\%)^{\mathrm{b}}$ & $29(9.6)$ & $15(7.7)$ \\
\hline $\mathrm{HD} \mathrm{Kt/V}$ value, mean $(\mathrm{SD})^{\mathrm{a}}$ & $1.6(0.3)^{*}$ & $1.5(0.3)$ \\
\hline $\mathrm{PD} \mathrm{Kt} / \mathrm{V}$ value, mean $(\mathrm{SD})^{\mathrm{a}}$ & $2.4(1.0)$ & $2.1(0.3)$ \\
\hline Mean (SD) HD duration per session, $h$ & $4.0(0.4)$ & $3.9(0.4)$ \\
\hline \multicolumn{3}{|l|}{ Vitamin $\mathrm{D}$, mean $(\mathrm{SD})^{\mathrm{a}}$} \\
\hline 25-Hydroxyvitamin $\mathrm{D}, \mathrm{nmol} / \mathrm{L}$ & $58.6(32.9)$ & $59.0(29.8)$ \\
\hline 1,25-Hydroxyvitamin D, pmol/L & $36.8(28.7)$ & $36.3(36.1)$ \\
\hline \multicolumn{3}{|l|}{ Bone resorption markers, mean $(\mathrm{SD})^{\mathrm{a}}$} \\
\hline TRAP5b, U/L & $5.1(2.5)$ & $4.8(2.4)$ \\
\hline $\mathrm{CTx}, \mathrm{ng} / \mathrm{mL}$ & $3.1(2.4)$ & $2.9(2.3)$ \\
\hline \multicolumn{3}{|l|}{ Bone formation markers, mean $(\mathrm{SD})^{\mathrm{a}}$} \\
\hline Bone-specific alkaline phosphatase, $\mathrm{ng} / \mathrm{mL}$ & $15.1(10.7)$ & $15.4(15.5)$ \\
\hline Osteocalcin, $\mathrm{ng} / \mathrm{mL}$ & $14.7(16.5)$ & $12.7(13.9)$ \\
\hline Mean (SD) albumin, g/L & $40.9(3.2)$ & $41.2(3.2)$ \\
\hline Mean (SD) total protein, $\mathrm{g} / \mathrm{L}$ & $67.2(5.4)$ & $68.1(5.8)$ \\
\hline
\end{tabular}

sP-controlled patients were defined as full analysis set patients who achieved a serum phosphorus level of $\leq 5.5$ $\mathrm{mg} / \mathrm{dL}$ at week 52. sP-uncontrolled were defined as full analysis set patients who did not achieve this serum phosphorus level. CTx, carboxyterminal cross-linking telopeptide; ESRD, end-stage renal disease; HD, hemodialysis; $\mathrm{K}$, dialyzer clearance of urea; $\mathrm{PD}$, peritoneal dialysis; ROW, rest of world; SD, standard deviation; sP, serum phosphorus; $t$, dialysis time; TRAP5b, tartrate-resistant acid phosphatase $5 \mathrm{~B}$; V, volume of distribution of urea. ${ }^{*} p<0.05 .{ }^{\mathrm{a}}$ Wilcoxon rank sum test. ${ }^{\mathrm{b}}$ Cochran-Mantel-Haenszel test. ${ }^{\mathrm{c}}$ Time since ESRD is the difference between the date of ESRD diagnosis and the date of the screening visit. ${ }^{\mathrm{d}}$ Time since first dialysis is the difference between the date of the first dialysis and the date of the screening visit for initial 24-week phase 3 study. 
week 24 were maintained to week 52 . This was not the case in the sP-uncontrolled patient group, where initial reductions observed at week 24 were not maintained.

A separate analysis of the sucroferric oxyhydroxide group and sevelamer group found significantly lower baseline levels and greater reductions in serum phosphorus at week 24 and week 52 in sP-controlled versus sPuncontrolled patients within both treatment groups $(p<$ 0.05 ; online suppl. Fig. 1 ). Similar changes in serum phosphorus were also observed between the sP-controlled and sP-uncontrolled patient groups in the SAS ( $p<0.001$ for week 24 and 52 time points; Fig. 2a).

\section{Serum iPTH}

Mean serum iPTH levels decreased from baseline to week 24 in both the sP-controlled and sP-uncontrolled patient groups (Fig. 1b). However, by week 52, these reductions in $\mathrm{iPTH}$ were only maintained in the sP-controlled group, with an overall increase in iPTH levels observed in the sP-uncontrolled group. This difference between the sP-controlled and sP-uncontrolled patient groups was statistically significant at week $52(p<0.001)$. Significantly greater reductions in iPTH at week 52 among patients with controlled versus uncontrolled serum phosphorus were also observed within the sucroferric oxyhydroxide and sevelamer groups $(p<0.01$; online suppl. Fig. 2 ). In the SAS, mean iPTH decreased from baseline to week 24 among patients who achieved serum phosphorus control, but remained unchanged among patients in the sP-uncontrolled group. By week 52, mean iPTH had returned to baseline levels in the sP-controlled group, but had increased in the sP-uncontrolled group (Fig. 2b).

\section{Serum FGF-23}

Serum FGF-23 concentrations decreased from baseline to week 24 to a similar extent in sP-uncontrolled and sPcontrolled patients. However, at week 52, significantly greater reductions from baseline were observed in $\mathrm{sP}$-controlled versus sP-uncontrolled patients ( $p<0.001$; Fig. 1c). In the sucroferric oxyhydroxide group, significantly greater decreases from baseline in FGF-23 were observed among sP-controlled versus sP-uncontrolled patients at week 52 $(p<0.001)$. In the sevelamer group, the decrease in FGF-23 from baseline was significantly greater in $\mathrm{sP}$-uncontrolled versus $\mathrm{sP}$-controlled patients at week $52(p<0.001$; online suppl. Fig. 3). In the SAS, baseline median FGF-23 level was significantly higher among sP-uncontrolled versus sPcontrolled patients $(p<0.001$; Fig. $2 c)$. Greater decreases in median FGF-23 were observed in sP-controlled versus sP-uncontrolled patients at weeks 24 and 52.

\section{Nutritional Parameters}

In the MAS, mean serum albumin decreased from baseline in both the sP-controlled and sP-uncontrolled patient groups at week 24 ( -0.13 vs. $-0.30 \mathrm{~g} / \mathrm{L}$, respectively) and week $52(-0.19$ vs. $-0.34 \mathrm{~g} / \mathrm{L})$; there were no statistically significant differences between the groups at both time points. In the SAS, change in mean albumin from baseline differed significantly between sP-controlled versus sP-uncontrolled patients at week $24(-0.22$ vs. $+0.33 \mathrm{~g} / \mathrm{L} ; p<0.05)$; however, no significant difference was observed at week $52(-0.16$ vs. $+0.01 \mathrm{~g} / \mathrm{L})$.

In the MAS, there was no statistically significant difference between sP-controlled and sP-uncontrolled patients for change in serum total protein from baseline to week 24 ( +0.45 vs. $-0.19 \mathrm{~g} / \mathrm{L}$ ) or week 52 (+0.18 vs. +0.10 $\mathrm{g} / \mathrm{L})$. In the SAS, differences in the change in serum total protein between sP-controlled versus sP-uncontrolled patients were also nonsignificant at week $24(+0.32$ vs. $+0.07 \mathrm{~g} / \mathrm{L})$ and week $52(+0.24$ vs. $-0.36 \mathrm{~g} / \mathrm{L})$.

\section{Concomitant Vitamin D and Calcimimetic Therapy \\ Use}

The proportion of patients receiving concomitant active vitamin D therapy (alfacalcidol, calcitriol, doxercalciferol, or paricalcitol) was significantly higher in the sPcontrolled group (79.5\%), compared with the sP-uncontrolled group $(68.7 \% ; p=0.007)$. A higher rate of active vitamin $\mathrm{D}$ therapy use among sP-controlled patients (76.1\%) versus sP-uncontrolled patients $(63.6 \%$; $p=$ 0.004 ) was also observed in the SAS. The proportion of patients receiving concomitant cinacalcet therapy during the study was similar in the sP-controlled and sPuncontrolled groups $(5.3 \%$ and $3.6 \%$, respectively; $p=$ $0.377)$.

Fig. 1. Concentrations and changes from baseline in mean (SD) serum phosphorus (a), mean (SD) iPTH (b), and median (25th/75th percentile) FGF-23 (c) for sP-controlled patients and sP-uncontrolled patients (main analysis set, $N=497$ ). $\mathbf{a} * p<0.001$ compared with sP-uncontrolled patients (baseline-adjusted ANO-

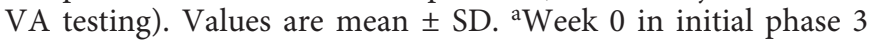
study. ${ }^{\text {b}}$ Extension study week 28 result. sP, serum phosphorus. b ${ }^{*} \mathrm{p}<0.001$ compared with sP-uncontrolled patients (baselineadjusted ANOVA testing). Values are mean \pm SD. ${ }^{\text {a Week }} 0$ in initial phase 3 study. ${ }^{b}$ Defined as extension study week 28 result. iPTH, intact parathyroid hormone; $s \mathrm{P}$, serum phosphorus. $\mathbf{c}^{*} p<$ $0.05,{ }^{* *} p<0.001$ compared with sP-uncontrolled patients (baseline-adjusted generalized linear model on rank data). Values are median ( \pm 25 th $/ 75$ th percentiles). ${ }^{\text {a Week } 0}$ in initial phase 3 study. ${ }^{b}$ Defined as extension study week 28 result. FGF-23, fibroblast growth factor-23; sP, serum phosphorus.

(For figure see next page.) 


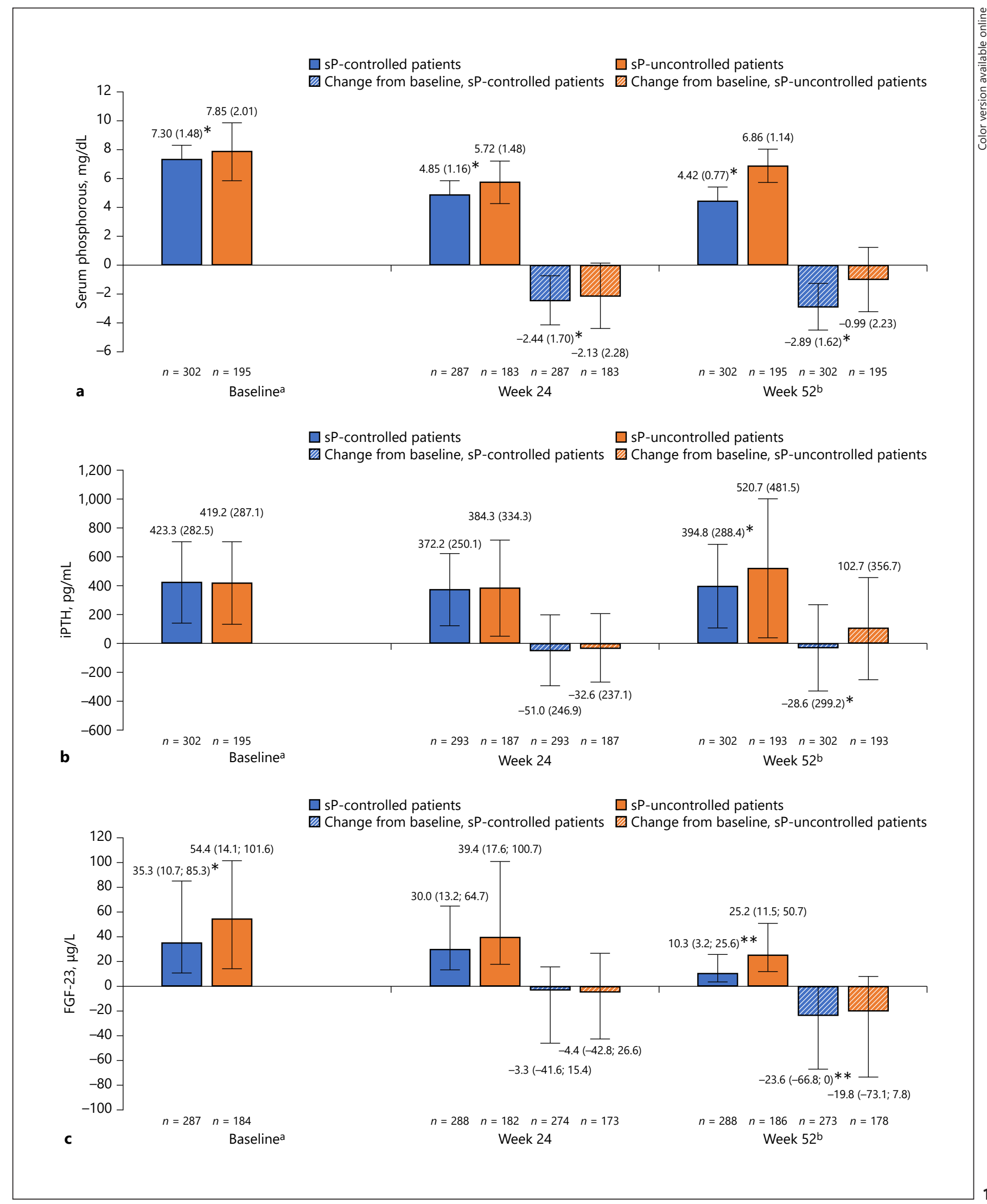


Treatment Adherence and Phosphate Binder Dose

Adherence rates to phosphate binder treatment over 1 year were similar between the sP-controlled and sPuncontrolled patients $(90.5 \%$ and $86.2 \%$, respectively; $p=0.533$ ). Average daily phosphate binder pill burden (mean $\pm \mathrm{SD}$ ) was lower for sP-controlled versus sP-uncontrolled patients in the sucroferric oxyhydroxide group (3.6 \pm 1.2 vs. $4.0 \pm 1.2$ tablets/day; $p=0.020)$ and sevelamer group ( $8.7 \pm 3.3$ vs. $9.5 \pm 3.9$ tablets/day; $p=$ 0.171). Comparisons of maximum daily phosphate binder doses showed that the proportion of patients receiving the highest maximum dose of sucroferric oxyhydroxide $(3.0 \mathrm{~g} /$ day) or sevelamer ( $14.4 \mathrm{~g} /$ day) was higher in the sP-uncontrolled group versus the sP-controlled group (Fig. 3).

\section{Predictors of Serum Phosphorus Control - Logistic Regression}

The logistic regression model identified baseline serum phosphorus levels, concomitant use of active vitamin D therapy (no vs. yes), and baseline BMI as significant predictors of serum phosphorus control $(\leq 5.5 \mathrm{mg} / \mathrm{dL})$ at week 52 (Table 2). Patients who had higher serum phosphorus levels at baseline were less likely to achieve serum phosphorus control at week 52, with each unit increase $(1 \mathrm{mg} / \mathrm{dL})$ reducing the odds by a factor of 0.86 . In other words, a patient with baseline serum phosphorus of 6.5 $\mathrm{mg} / \mathrm{dL}$ was 0.86 times less likely to achieve serum phosphorus control than a patient with baseline serum phosphorus of $5.5 \mathrm{mg} / \mathrm{dL}$. For patients who received concomitant active vitamin $\mathrm{D}$ during the study, the odds of achieving serum phosphorus control was 1.95 higher, compared with patients who were not receiving concomitant vitamin $\mathrm{D}$ therapy. Patients with higher BMI at baseline were less likely to achieve serum phosphorus control at week 52 , with a 0.96 decrease in the odds per unit increase $\left(1 \mathrm{~kg} / \mathrm{m}^{2}\right)$ of BMI.

\section{Safety}

Similar proportions of sP-controlled and sP-uncontrolled patients in the MAS reported at least one TEAE during the study ( $86.8 \%$ and $89.7 \%$, respectively; Table 3 ). Incidences of serious TEAEs were also comparable between sP-controlled and sP-uncontrolled patient groups ( $24.5 \%$ vs. $27.7 \%$, respectively), as were rates of severe TEAEs, treatment-related TEAEs, and TEAEs leading to hospitalization.

Because the MAS definition required patients to have a serum phosphorus level registered at week 52, no patients who prematurely discontinued treatment were in- cluded in this analysis. For the same reason, no patients who had experienced a fatal TEAE during the treatment period were included in the analysis. One fatal TEAE (cardiorespiratory arrest in a sevelamer-treated patient) was reported in the sP-controlled patient group during the follow-up period, and none in the sP-uncontrolled group. The most frequent TEAEs were gastrointestinal (GI; $46.3 \%$ of patients overall). The proportion of sP-controlled and sP-uncontrolled patients reporting GI TEAEs was similar, as was the proportion of those reporting individual GI TEAEs.

\section{Discussion and Conclusion}

This post hoc analysis of a 52-week phase 3 study identified several factors associated with achievement of serum phosphorus control among patients randomized to sucroferric oxyhydroxide or sevelamer. Univariate comparison of baseline characteristics found that sP-controlled patients were on average older than the sP-uncontrolled group. There is evidence from studies that serum phosphorus is more challenging to control in younger patients, due in part to a lower rate of phosphate binder treatment adherence [18] and a higher dietary phosphate intake and reduced dietary adherence in this patient population $[19,20]$. However, the current analysis did not show any significant differences in adherence rates to sucroferric oxyhydroxide or sevelamer between the sP-controlled and sP-uncontrolled patient groups.

sP-uncontrolled patients had significantly higher serum phosphorus levels at baseline than $\mathrm{sP}$-controlled patients, and there are several potential factors that may explain this difference. The higher level of dialysis adequacy (hemodialysis Kt/V value) at baseline among he-

Fig. 2. Supporting analysis of concentrations and changes from baseline in mean (SD) serum phosphorus (a), mean (SD) iPTH (b), and median (25th/75th percentile) FGF-23 (c) for sP-controlled and sPuncontrolled patients (supporting analysis set, $N=569$ ). $\mathbf{a} * p<0.001$ compared with sP-uncontrolled (baseline-adjusted ANOVA). Values are mean $\pm \mathrm{SD}$. ${ }^{a}$ Week 0 in initial phase 3 study. ${ }^{b}$ Defined as extension study week 28 result. sP, serum phosphorus. b $^{*} p<0.01$, $* * \mathrm{p}<0.001$ compared with sP-uncontrolled (baseline-adjusted ANOVA). Values are mean \pm SD. ${ }^{\text {a Week }} 0$ in initial phase 3 study. ${ }^{b}$ Defined as extension study week 28 result. iPTH, intact parathyroid hormone; sP, serum phosphorus. $c^{*} p<0.001$ compared with sPuncontrolled patients (baseline-adjusted generalized linear model on rank data). Values are median ( \pm 25 th $/ 75$ th percentiles). ${ }^{\text {a }}$ Week 0 in initial phase 3 study. ${ }^{\text {b}}$ Defined as extension study week 28. FGF-23, fibroblast growth factor-23; sP, serum phosphorus.

(For figure see next page.) 


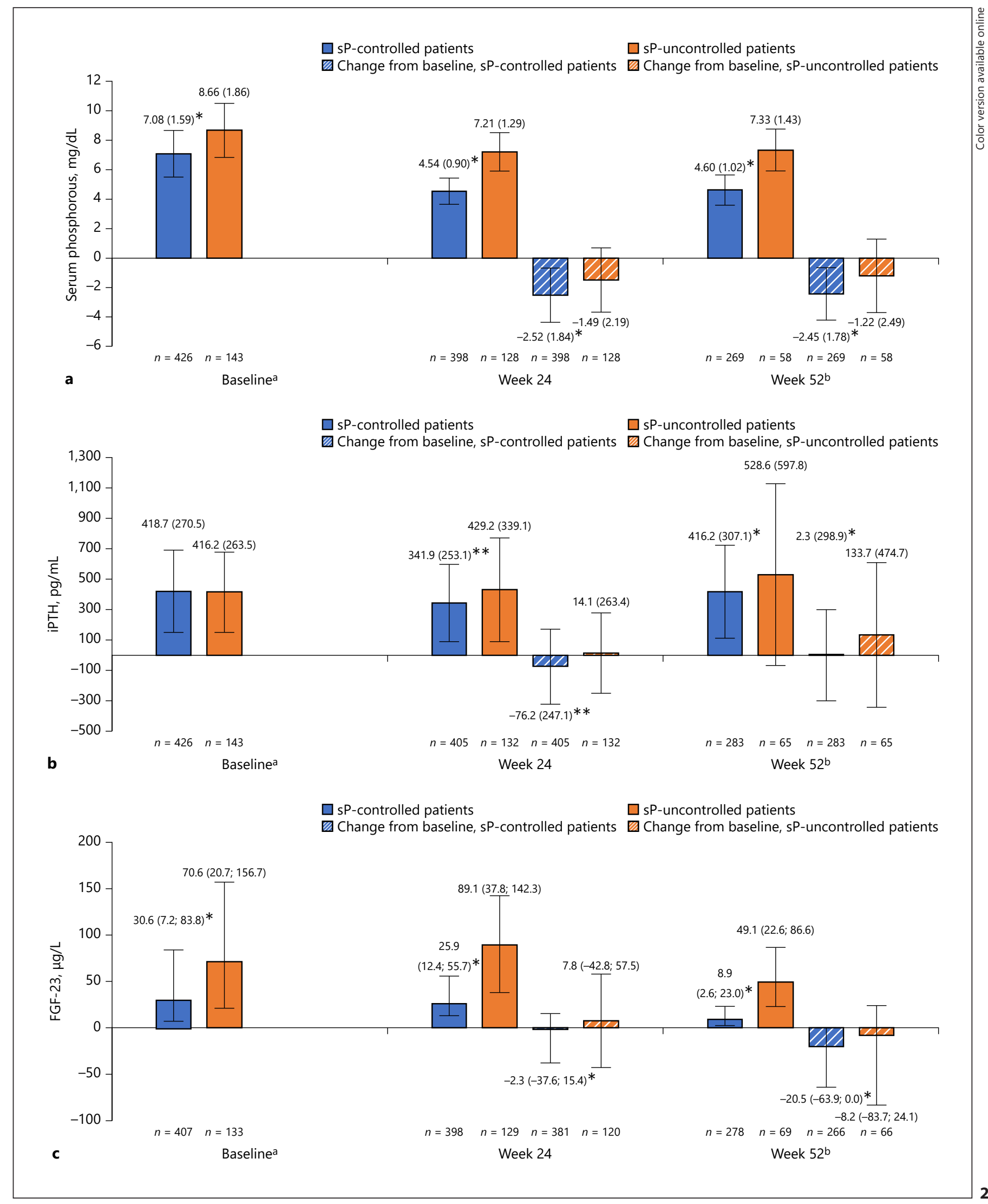

sP Control with Sucroferric Oxyhydroxide 
Fig. 3. Comparison of maximum daily phosphate binder dose administered to sPcontrolled and sP-uncontrolled patients in the sucroferric oxyhydroxide (a) and sevelamer carbonate (b) groups (main analysis set, $N=497$ ). sP, serum phosphorus.

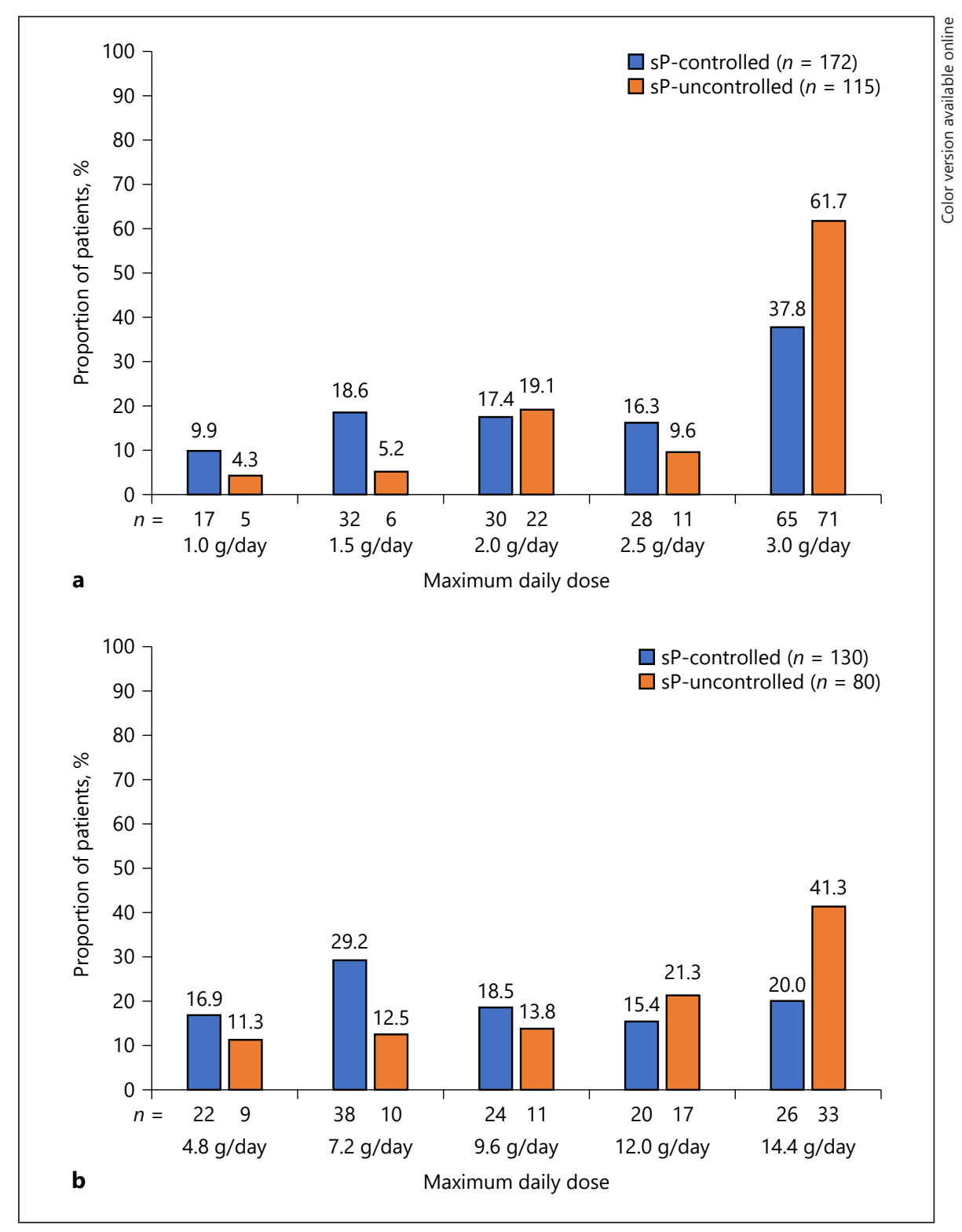

modialysis patients who achieved serum phosphorus control may have contributed to the lower mean serum phosphorus levels at baseline. Furthermore, higher baseline serum phosphorus levels among the sP-uncontrolled patients may be reflective of higher dietary phosphate intake or lower adherence to dietary advice. However, data on dietary intake at baseline or during the study are not available. The multivariate logistic regression analysis showed baseline serum phosphorus level was a significant predictor of serum phosphorus control. This is not an unexpected finding because patients who began the study with a higher serum phosphorus level required a greater reduction in absolute serum phosphorus levels in order to achieve serum phosphorus control by week 52 .

In the multivariate analysis, baseline BMI was found to be a significant predictor of patients achieving serum phosphorus control. Patients with higher BMI may have had a higher dietary intake (and thus higher phosphate load), compared with patients with lower BMI. Thus, serum phosphorus may have been more difficult to control in this patient population.

sP-controlled patients also displayed significantly greater reductions in serum iPTH and FGF-23 compared with sP-uncontrolled patients, and these findings may, in part, reflect the greater reductions in serum phosphorus 
Table 2. Predictors of achieving serum phosphorus control at week 52 (sP-controlled vs. sP-uncontrolled) from multivariate logistic model analysis (main analysis set, $N=497$ )

\begin{tabular}{llrr}
\hline Variable & Odds ratio & $\begin{array}{l}\text { Lower 95\% } \\
\text { confidence limit }\end{array}$ & $\begin{array}{l}\text { Upper 95\% } \\
\text { confidence limit }\end{array}$ \\
\hline Serum phosphorus at baseline, mg/dL & 0.86 & 0.765 & 0.960 \\
BMI at baseline, $\mathrm{kg} / \mathrm{m}^{2}$ & 0.96 & 0.937 & 0.992 \\
Concomitant active vitamin D (no vs. yes) & 0.51 & 0.328 & 0.0079 \\
\hline
\end{tabular}

BMI, body mass index.

Table 3. Summary of TEAEs and specific GI-related TEAEs occurring in $\geq 5 \%$ of patients (main analysis set, $N=$ 497)

\begin{tabular}{lccc}
\hline & $\begin{array}{l}\text { sP-controlled patients } \\
(n=302) \\
n(\%)\end{array}$ & $\begin{array}{l}\text { sP-uncontrolled patients } \\
(n=195) \\
n(\%)\end{array}$ & $\begin{array}{l}\text { Total } \\
(N=497) \\
n(\%)\end{array}$ \\
\hline Any TEAE & $262(86.8)$ & $175(89.7)$ & $437(87.9)$ \\
Any severe TEAE & $35(11.6)$ & $28(14.4)$ & $63(12.7)$ \\
Any serious TEAE & $74(24.5)$ & $54(27.7)$ & $128(25.8)$ \\
Any treatment-related TEAE & $92(30.5)$ & $60(30.8)$ & $152(30.6)$ \\
Any AE leading to death & $1(0.3)$ & $0(0)$ & $124(24.9)$ \\
Any TEAE leading to hospitalization & $71(23.5)$ & $93(27.2)$ & $230(46.3)$ \\
Any GI TEAE & $139(46.0)$ & $35(17.9)$ & $90(18.1)$ \\
$\quad$ Diarrhea & $55(18.2)$ & $24(12.3)$ & $49(9.9)$ \\
Nausea & $25(8.3)$ & $18(9.2)$ & $40(8.0)$ \\
Vomiting & $22(7.3)$ & $9(6.2)$ & $38(7.6)$ \\
Feces discolored & $26(8.6)$ & $10(5.1)$ & $26(5.2)$ \\
Constipation & $17(5.6)$ & $20(4.0)$ \\
Dyspepsia & $10(3.3)$ & & $20.6)$ \\
\hline
\end{tabular}

sP-controlled were defined as patients who achieved a serum phosphorus level of $\leq 5.5 \mathrm{mg} / \mathrm{dL}$ at week 52 . GI, gastrointestinal; sP, serum phosphorus; TEAE, treatment-emergent adverse event.

levels among sP-controlled patients, compared with sPuncontrolled patients. Furthermore, the proportion of patients who received concomitant active vitamin $\mathrm{D}$ during the study was higher among sP-controlled versus sPuncontrolled patients, and multivariate analysis showed that patients who received concomitant active vitamin D therapy in this post hoc analysis had 1.95 -fold higher odds of achieving serum phosphorus control than patients who did not receive active vitamin $\mathrm{D}$ therapy. These findings indicate active vitamin D use is a significant predictor of sP control. Higher concomitant active vitamin $\mathrm{D}$ use among sP-controlled patients may help to explain the more sustained serum iPTH reductions observed in this group. Furthermore, observational studies in maintenance HD patients have shown that elevated levels of PTH are associated with hyperphosphatemia, possibly due to increased phosphorus efflux from the bone. Therefore, better control of PTH levels may improve serum phosphorus control in dialysis patients, and this may have contributed to the findings in the present study. The PTH-lowering effect of active vitamin D may in turn have offset the documented effect of increased intestinal phosphate absorption observed with active vitamin D therapy $[21,22]$.

Other factors that were evaluated but did not differ significantly between sP-controlled and sP-uncontrolled patients included bone turnover markers, phosphate binder dose, and treatment adherence. In clinical practice, achievement of serum phosphorus control with phosphate binder therapy may be more challenging among patients with high bone turnover. However, comparison of baseline levels of bone resorption (tartrate-re- 
sistant acid phosphatase $5 \mathrm{~b}$ and carboxyterminal crosslinking telopeptide) and bone formation (bone-specific alkaline phosphatase and osteocalcin) markers found no significant differences between the sP-controlled and sPuncontrolled groups.

Comparison of the dosages of sucroferric oxyhydroxide and sevelamer administered suggested that failure to achieve serum phosphorus control was not related to underdosing during the study. Average daily sucroferric oxyhydroxide or sevelamer pill burden was numerically lower for sP-controlled patients versus sP-uncontrolled patients. Furthermore, comparison of maximum daily doses of phosphate binders administered showed that the proportion of patients who received the highest maximum dose of sucroferric oxyhydroxide $(3.0 \mathrm{~g} /$ day $)$ or sevelamer ( $14.4 \mathrm{~g} /$ day) during the study was higher in the sP-uncontrolled group, compared with the sP-controlled group. The analysis showed no difference in adherence rates between sP-controlled and sP-uncontrolled patients; however, nonadherence to phosphate binder therapy cannot be excluded as a factor contributing to lack of serum phosphorus control.

The supporting analysis of efficacy used a more nuanced definition of serum phosphorus control, aiming to include patients based on their achievement of serum phosphorus control over the trial period rather than focusing only on the serum phosphorus value at week 52 . This analysis could also assess patients without an available serum phosphorus value at week 52 . In most cases, the definition used in the supporting analysis showed clearer differences between sP-controlled and sP-uncontrolled patients, with regard to the changes in the levels of serum phosphorus, iPTH, and FGF-23, compared with using the treatment target at week 52 alone. However, the overall findings were consistent with those observed for the MAS.

The upper value of the KDOQI target range (3.5-5.5 $\mathrm{mg} / \mathrm{dL}$ ) was selected to define patients achieving serum phosphorus control in this analysis [9]. However, other clinical guidelines recommend lower targets for serum phosphorus. For example, the 2017 KDIGO clinical practice guidelines recommend "lowering elevated phosphate levels toward the normal range" (typically $2.5-4.5 \mathrm{mg} / \mathrm{dL}$ ) $[23,24]$. An analysis of the COSMOS study cohort, comprising 6,797 adult chronic hemodialysis patients from 20 European countries, identified serum phosphorus levels between 3.6 and $5.2 \mathrm{mg} / \mathrm{dL}$ as being associated with the lowest mortality [25]. However, prospective randomized clinical studies are still required to accurately define the optimal target range of serum phosphorus to confer improved survival.
This study has several limitations. It was a post hoc analysis; therefore, the original study was not powered to identify differences between sP-controlled and sP-uncontrolled patients. No data are available on dietary phosphate intake, and hence the impact of this factor on serum phosphorus levels is not clear. Treatment adherence was calculated on the basis of the number of tablets returned by patients; it is acknowledged that this method of assessment has limited reliability, and so the findings should be interpreted with caution.

\section{Conclusions}

In this post hoc analysis, baseline serum phosphorus level, BMI at baseline, and concomitant use of active vitamin D were significantly predictive of serum phosphorus control among patients treated with sucroferric oxyhydroxide or sevelamer. Patients who achieved serum phosphorus control with these phosphate binders were on average older than those who did not. Overall, the findings indicate that hyperphosphatemia is more challenging to manage in younger patients with relatively high serum phosphorus levels; therefore, closer monitoring and management of serum phosphorus levels may be required in this patient population.

\section{Acknowledgement}

Medical writing assistance was provided by AXON Communications, London, UK.

\section{Statement of Ethics}

The protocol of the phase 3 study (NCT01324128) and extension (NCT01464190) was reviewed by Independent Ethics Committees or Institutional Review Boards, and the study was conducted in accordance with the Declaration of Helsinki Principles, the International Conference on Harmonisation E6 Guideline for Good Clinical Practice, and Committee for Proprietary Medicinal Products guideline (CPMP/ICH/135/95) and was compliant with the European Union Clinical Trial Directive (Directive 2001/20/ EC) and the Code of Federal Regulations for informed consent and protection of patient rights.

\section{Disclosure Statement}

A.C.C. has received consultancy fees or lecture fees from Vifor Pharma, Fresenius Medical Care, and Amgen. S.M.S. has received consultancy fees from OPKO, Vifor Pharma, Amgen, Fresenius 
Medical Care, Litholink Corp, and NPS Pharma and research funding from Abbott, Amgen, and Shire. A.R. has received consultancy fees from Fresenius Medical Care and Vifor Pharma and lecture and consultancy fees from Sanofi, Cytochroma/OPKO Health, Vifor Pharma, Satellite Healthcare, and Deltanoid. M.K. has received consulting fees or lecture fees from Vifor Pharma, Fresenius Medical Care, Amgen, AbbVie, Medice, Mitsubishi Pharma, Sanofi, and Shire. S.W. and A.P. are both employees of Vifor Pharma. J.F. has received consulting fees or lecture fees from AbbVie, Amgen, Chugai, Fresenius Medical Care, Sanofi, Shire, and Vifor Pharma.

\section{Funding Sources}

This study and medical writing assistance for the manuscript was funded by Vifor Pharma, Glattbrugg, Switzerland.

\section{Author Contributions}

All authors contributed toward the design of the study, the data interpretation, and drafting/revising the content of the manuscript. A.P. performed the statistical analysis.

\section{References}

1 Martin KJ, González EA. Prevention and control of phosphate retention/hyperphosphatemia in CKD-MBD: what is normal, when to start, and how to treat? Clin J Am Soc Nephrol. 2011;6(2):440-6.

2 Hruska KA, Seifert M, Sugatani T. Pathophysiology of the chronic kidney disease-mineral bone disorder. Curr Opin Nephrol Hypertens. 2015;24(4):303-9.

3 Block GA, Klassen PS, Lazarus JM, Ofsthun N, Lowrie EG, Chertow GM. Mineral metabolism, mortality, and morbidity in maintenance hemodialysis. J Am Soc Nephrol. 2004; 15(8):2208-18.

4 Gutiérrez OM, Mannstadt M, Isakova T, Rauh-Hain JA, Tamez H, Shah A, et al. Fibroblast growth factor 23 and mortality among patients undergoing hemodialysis. N Engl J Med. 2008;359(6):584-92.

5 Tentori F, Blayney MJ, Albert JM, Gillespie BW, Kerr PG, Bommer J, et al. Mortality risk for dialysis patients with different levels of serum calcium, phosphorus, and PTH: the Dialysis Outcomes and Practice Patterns Study (DOPPS). Am J Kidney Dis. 2008;52(3):51930.

6 Hutchison AJ, Smith CP, Brenchley PE. Pharmacology, efficacy and safety of oral phosphate binders. Nat Rev Nephrol. 2011; 7(10):578-89.

7 Barreto FC, de Oliveira RA, Oliveira RB, Jorgetti V. Pharmacotherapy of chronic kidney disease and mineral bone disorder. Expert Opin Pharmacother. 2011;12(17):2627-40.

8 Fernández-Martín JL, Carrero JJ, Benedik M, Bos WJ, Covic A, Ferreira A, et al. COSMOS: the dialysis scenario of CKD-MBD in Europe. Nephrol Dial Transplant. 2013;28(7):192235.

9 National Kidney Foundation. K/DOQI clinical practice guidelines for bone metabolism and disease in chronic kidney disease. Am J Kidney Dis. 2003;42(4 Suppl 3):S1-201.
10 Sekercioglu N, Thabane L, Díaz Martínez JP, Nesrallah G, Longo CJ, Busse JW, et al. Comparative effectiveness of phosphate binders in patients with chronic kidney disease: a systematic review and network meta-analysis. PLoS One. 2016;11(6):e0156891.

11 Jamal SA, Vandermeer B, Raggi P, Mendelssohn DC, Chatterley T, Dorgan M, et al. Effect of calcium-based versus non-calcium-based phosphate binders on mortality in patients with chronic kidney disease: an updated systematic review and meta-analysis. Lancet. 2013;382(9900):1268-77.

12 Renvela (sevelamer carbonate) tablet, film coated for oral use/for oral suspension. Highlights of Prescribing Information [cited 2019 August 20]. 2011. Available from: http:// www.accessdata.fda.gov/drugsatfda_docs/la bel/2011/022318s003,022127s008lbl.pdf.

$13 \mathrm{VELPHORO}^{\circ}$ (sucroferric oxyhydroxide) chewable tablet for oral use. Highlights of Prescribing Information [cited 2019 August 20]. 2014. Available from: http://www.accessdata. $\mathrm{fda} \cdot \mathrm{gov} / \mathrm{drugsatfda}$ _docs/label/2014/ 205109s001lbl.pdf.

14 Pennoyer A, Bridgeman MB. Ferric citrate (auryxia) for the treatment of hyperphosphatemia. P T. 2015;40(5):329-39.

15 Floege J, Covic AC, Ketteler M, Rastogi A, Chong EM, Gaillard S, et al. A phase III study of the efficacy and safety of a novel iron-based phosphate binder in dialysis patients. Kidney Int. 2014;86(3):638-47.

16 Floege J, Covic AC, Ketteler M, Mann JF, Rastogi A, Spinowitz B, et al. Long-term effects of the iron-based phosphate binder, sucroferric oxyhydroxide, in dialysis patients. Nephrol Dial Transplant. 2015;30(6):1037-46.

17 Ketteler M, Sprague SM, Covic AC, Rastogi A, Spinowitz B, Rakov V, et al. Effects of sucroferric oxyhydroxide and sevelamer carbonate on chronic kidney disease-mineral bone disorder parameters in dialysis patients. Nephrol Dial Transplant. 2019;34(7):1163-70.
18 Karamanidou C, Clatworthy J, Weinman J, Horne R. A systematic review of the prevalence and determinants of nonadherence to phosphate binding medication in patients with end-stage renal disease. BMC Nephrol. 2008;9:2.

19 Arenas MD, Malek T, Álvarez-Ude F, Gil MT, Moledous A, Reig-Ferrer A. [Phosphorus binders: Preferences of patients on haemodialysis and its impact on treatment compliance and phosphorus control]. Nefrologia. 2010; 30(5):522-30.

20 Umeukeje EM, Mixon AS, Cavanaugh KL. Phosphate-control adherence in hemodialysis patients: current perspectives. Patient Prefer Adherence. 2018;12:1175-91.

21 Cunningham J, Locatelli F, Rodriguez M. Secondary hyperparathyroidism: pathogenesis, disease progression, and therapeutic options. Clin J Am Soc Nephrol. 2011;6(4):913-21.

22 Zand L, Kumar R. The use of vitamin D metabolites and analogues in the treatment of chronic kidney disease. Endocrinol Metab Clin North Am. 2017;46(4):983-1007.

23 Ketteler M, Block GA, Evenepoel P, Fukagawa M, Herzog CA, McCann L, et al. Executive summary of the 2017 KDIGO chronic kidney disease-mineral and bone disorder (CKDMBD) guideline update: what's changed and why it matters. Kidney Int. 2017;92(1):26-36.

24 Kidney Disease: Improving Global Outcomes (KDIGO) CKD-MBD Work Group. KDIGO clinical practice guideline for the diagnosis, evaluation, prevention, and treatment of chronic kidney disease-mineral and bone disorder (CKD-MBD). Kidney Int Suppl. 2009; (113):S1-130.

25 Fernández-Martín JL, Martínez-Camblor P, Dionisi MP, Floege J, Ketteler M, London G, et al. Improvement of mineral and bone metabolism markers is associated with better survival in haemodialysis patients: the COSMOS study. Nephrol Dial Transplant. 2015; 30(9):1542-51. 